\title{
GAMBARAN RESILIENSI PERANTAU MINANGKABAU YANG BERWIRAUSAHA DI MEDAN
}

\author{
Mutia Maulidya dan Rika Eliana \\ Universitas Sumatera Utara
}

\begin{abstract}
ABSTRAK
Tujuan penelitian ini adalah mendapatkan gambaran resiliensi perantau dari suku Minangkabau yang berwirausaha di Kota Medan. Suku Minangkabau sebagai salah satu suku di Indonesia memiliki budaya merantau. Sebagian besar dilakukan saat merantau ialah berwirausaha. Saat merantau dan berwirausaha akan menghadapi beberapa kesulitan. Dalam berwirausaha dan merantau butuh adanya kemampuan resiliensi. Penelitian ini melibatkan 296 wirausahawan perantau Minangkabau yang bertempat tinggal di Medan. Skala yang digunakan dalam penelitian ini ialah adaptasi dari Resiliency Quotient Test (RQ test) oleh Reivich dan Shatte (2002). Hasil penelitian menunjukkan mayoritas perantau Minangkabau yang berwirausaha memiliki resiliensi yang tergolong tinggi. Tidak ada perantau Minangkabau yang berwirausaha memiliki resiliensi yang tergolong rendah.
\end{abstract}

Kata-kata kunci: Resiliensi, Minangkabau, merantau, wirausaha

\section{RESILIENCY OF MINANGKABAU OUTMIGRANTS WHO ENGGAGES IN ENTREPRENEURSHIPS IN MEDAN}

\begin{abstract}
The aim of the present research is to get an overview of the Minangkabau outmigrants who enggage in entrepreneurship resilience level in Medan. The Minangkabau is one of Indonesia's ethnic group who has the outmigrating culture. Most live by enggaging in entrepreneurships while outmigrating. The outmigrating their enggagement in entrepreneurship required them to have sufficient resiliency. The present research involved 296 Minangkabau outmigrant entrepreneurs who lives in Medan. The scale used in the present research was an adaptation of the Resiliency Quitient Test (RQ test) developed by Reivichand Shatte (2002). The results shows that the majority of Minangkabau outmigrant entrepreneurs possessed high resiliency. No participants in this research that shows low level of resiliency.
\end{abstract}

Keywords: Resiliency, Minangkabau, outmigration, entrepreneurhips

Tradisi migrasi atau yang biasa disebut merantau oleh suku Minangkabau ke berbagai kota masih sangat kuat (Pelly, 1998). Naim (dalam Ibrahim, 1984) menjelaskan bahwa tidak hanya suku Minangkabau saja yang melakukan migrasi tetapi yang mencolok ialah tingkat migrasinya terus meningkat. Menurut Amir (1999) merantau menjadi jalan keluar atas pertentangan pembagian harta warisan berdasarkan adat dan agama Islam. Harta yang didapatkan dari perantauan dapat dibagikan secara agama Islam. Tradisi merantau menyebabkan orang Minangkabau tidak terlalu tergantung dengan harta pusaka (harta warisan) yang diwariskan hanya pada wanita secara adat.

*Korespondensi mengenai penelitian ini dapat dilayangkan kepada Rika Eliana melalui email: rebarus@yahoo.com
Perantau Minangkabau menghadapi berbagai kesulitan saat merantau dan berwirausaha. Pelly (dalam Ibrahim, 1984) menyatakan ada banyak hambatan yang akan dihadapi saat merantau. Mulai dari tata-bahasa yang berbeda, adat istiadat dan norma yang berbeda dengan daerah asal perantau tersebut. Suster (2009) menyatakan kesulitan yang biasa dialami saat berwirausaha seperti tidak ada pembeli, kegagalan produk yang dijual, tidak ada pemberi modal, dan persaingan bisnis lain. Barringer \& Ireland (2010) menambahkan bahwa kekhasan dalam berwirausaha ialah mencoba sesuatu hal yang baru, dan kegagalan merupakan hal yang sangat alami terjadi.

Kemampuan seseorang untuk mengatasi kesulitan atau tant angan yang

Rekomendasi mensitasi:

Maulidya, M., \& Eliana, R. (2013). Gambaran resiliensi perantau Minangkabau yang berwirausaha di Medan. Psikologia, 8(2), 3439. 
terjadi di kehidupan dan bukan lari dari kesulitan tersebut diistilahkan resiliensi oleh Grotberg (2002). Reivich dan Shatte (2002) menambahkan resiliensi dibutuhkan untuk dapat melalui kesulitan yang menimpa seseorang dan bangkit kembali sehingga tidak menjadi putus asa. Resiliensi dibutuhkan saat bermigrasi yang mana pada penelitian ini diistilahkan merantau (Rutter dalam Reich, Zautra \& Hall, 2010). Dalam bermigrasi atau merantau individu harus beradaptasi dengan lingkungan, bahasa, bahkan makanan dan lain-lain. Grotber (2002) juga menambahkan bahwa budaya merupakan suatu faktor yang dapat mempromosikan resiliensi. Dalam penelitian ini budaya yang dimaksud ialah budaya yang dimiliki oleh suku Minangkabau. Ibrahim (1984) menyatakan bagi orang Minangkabau, adalah penting bagi orang Minangkabau untuk bersikap tidak ragu untuk hidup di rantau yang penuh dengan kesulitan.

\section{Resiliensi dan berwirausaha}

Grotberg (1999) menyatakan bahwa resiliensi merupakan kapasitas manusia untuk menghadapi, mengatasi, menjadi kuat dan bahkan berubah dikarenakan pengalaman yang sulit. Setiap individu mempunyai kapasitas untuk melakukan resiliensi, belajar bagaimana menghadapi kegagalan dalam hidup yang tidak dapat dihindari, dan berubah karena pengalaman tersebut.

Reivich dan Shatte (2002) mengungkapkan bahwa resiliensi merupakan kapasitas untuk merespon dengan baik dan menggunakan cara produktif dalam menghadapi trauma. Resiliensi diperlukan dalam menghadapi stress. Kemampuan resiliensi penting untuk memperluas dan menambah pengalaman individu dalam menyelesaikan suatu permasalahan. Dalton, Elias dan Wandersman (2007) menambahkan resiliensi ialah kemampuan yang memungkin seseorang keluar dari keadaan penuh tekanan. Luthar (dalam Reich,
Zautra \& Hall 2010) menyatakan bahwa resiliensi ialah kemampuan adaptasi positif dalam menghadapi pengalaman sulit atau trauma.

Ada beberapa faktor yang dapat mempengaruhi resiliensi, yakni menurut Bynener et al (dalam Schoon, 2006) ialah atribut-atribut individual, karakteristik keluaraga, dan aspek konteks sosial yang lebih luas (selain orang tua, tetangga, teman, dan komunitas). Sedangkan menutup Grotberg (2003) faktor yang mempengaruhi ialah dukungan eksternal ( $I$ have), kekuatan pribadi ( $I$ am), dan kemampuan interpersonal dan kemampuan pemecahan masalah (I can).

Konsep resiliensi juga sering digunakan dalam studi ketahanan dan peralihan karir untuk mendeskripsikan individu tetap dengan cita-cita karir saat menghadapi kesulitan yang dialami (De Vries \& Shields, 2005). Menurut Siebert (2005) pekerjaan seperti bekerja di perusahaan, usaha kecil atau wirausaha, agen publik, jasa profesional, dan kerja mandiri butuh kemampuan resiliensi. Resiliensi menjadi hal yang paling penting untuk bertahan dan sukses pada orang yang memiliki suatu wirausaha, dibandingkan orang yang hanya memiliki pengetahuan teknis atau praktek tentang bisnisnya.

Wirausaha didefinisikan sebagai individu yang mengambil resiko di antara pembeli dan penjual atau individu yang mengerjakan suatu tugas seperti memulai suatu usaha baru (Bolton \& Thompson dalam Barringer \& Ireland, 2010). Dewanti (2008) menyatakan wirausaha berarti kemampuan memiliki ide kreatif dan berperilaku dapat memperjuangkan usaha dengan keputusan pengambilan resiko secara bijak untuk meningkatkan kualitas hidup. Wirausahawan berarti orang-orang yang mampu menjawab tantangantantangan dan memanfaatkan peluangpeluang yang ada.

De Vries dan Shields (2005) menyatakan resiliensi membuat keahlian, pengetahuan, dan kemampuan saling 
bekerja sama untuk mengatasi tantangantantangan yang terjadi dalam suatu usaha. Hasil penelitian oleh Sun et al (2011) menunjukkan bahwa resiliensi sebagai faktor penting yang menjadi sumber dan keahlian mendasar bagi wirausahawan agar bisnis yang dijalankan sukses. Berdasarkan latar belakang yang dipaparkan peneliti merasa perlu untuk meneliti mengenai gambaran resiliensi perantau Minangkabau yang berwirausaha di Medan.

\section{METODE}

\section{Partisipan}

Partisipan adalah 296 orang perantau Minangkabau yang berwirausaha di Medan. Partisipan diambil dengan teknik convenience sampling. Partisipan lebih dominan berjenis kelamin laki-laki yaitu $73 \%$ (215 orang). Rentang usia yang diperoleh dari umur 19 sampai 73 tahun yang didominasi oleh partisipan berusia kategori dewasa madya (40 tahun-65 tahun) sebanyak 53\% (157 orang). Partisipan yang berstatus pendidikan didominasi SMA sederajat yakni 51\% (152 orang). Berdasarkan status pernikahan partisipan yang sudah menikah sebanyak $86 \%$ (254 orang).

\section{Alat ukur}

Penelitian ini menggunakan skala yang diadaptasi dari Resiliency Quotient Test (RQ Test) oleh Reivich \& Shatte (2002) dengan menambahkan 36 aitem dan menggunakan pengukuran skala Likert $(\alpha$ $=.88$; corrected item-to-total correlation $=$ .26 sampai .64). Peneliti menggunakan lima rentang yaitu Tidak Sesuai Menggambarkan Diri Saya (Tidak Sesuai), Kadang-kadang Sesuai Menggambarkan Diri Saya (Kadang-Kadang Sesuai), Cukup Sesuai Menggambarkan Diri Saya (Cukup Sesuai), Sesuai Gambaran Diri Saya (Sesuai), Paling Sesuai Menggambarkan Diri Saya (Paling Sesuai). Validitas alat ukur didapat melalui professional judgement oleh dua dosen yang menguasai teori. Skala Resiliency Quotient Test (RQ Test) oleh Reivich \& Shatte (2002) memiliki tujuh dimensi yakni regulasi emosi, kontrol impuls, optimisme, analisa kausal, empati, efikasi diri (self-efficacy), dan pencapaian (reaching out).

\section{Prosedur}

Penelititan ini diawali dengan melakukan wawancara awal untuk mencari data yang terkait dengan variabel penelitian dengan pewirausaha yang bersuku Minangkabau dan tokoh masyarakat Minangkabau. Penyebaran skala psikologis berdasarkan convenience sampling diberikan kepada 314 orang perantau Minangkabau. Skala yang kembali diisi oleh 296 orang. Partisipan mengisi secara sukarela.

\section{HASIL}

\section{Resiliensi wirausahawan perantau Minangkabau}

Berdasarkan analisa data didapatkan resiliensi perantau Minangkabau yang berwirausaha di Medan dapat dilihat dari Tabel 1.

Untuk mendapatkan gambaran lebih lanjut mengenai kondisi resiliensi para partisipan, peneliti akan membandingkan nilai skor partisipan di masing-masing dimensi resiliensi, yaitu regulasi emosi, kontrol impuls, optimisme, analisa kausal, empati, self-efficacy, dan pencapaian. Gambaran kategori resiliensi perantau Minangkabau yang berwirausaha di Medan berdasarkan dimensi resiliensi dapat dilihat dari Tabel 2.

Dari Tabel 2 dapat dilihat bahwa dimensi yang memiliki nilai mean paling tinggi ialah dimensi efikasi diri (selfefficacy) dan dimensi pencapaian (reaching out). Sedangkan dimensi yang mendapatkan nilai mean paling rendah ialah empati. 
Tabel 1 Frekuensi berdasarkan tingkat resiliensi wirausahawan perantau Minangkabau

\begin{tabular}{llcc}
\hline Kategori & $\begin{array}{l}\text { Kriteria } \\
\text { kategorisasi } \\
\text { jenjang }\end{array}$ & $\mathbf{N}$ & Persentase \\
\hline $\begin{array}{l}\text { Tinggi } \\
X \geq(\mu+1 \sigma)\end{array}$ & $X \geq 132$ & 255 & $86 \%$ \\
$\begin{array}{l}\text { Menengah } \\
(\mu-1 \sigma) \leq x \\
<(\mu+1 \sigma)\end{array}$ & $84 \leq X \leq 132$ & 41 & $14 \%$ \\
$\begin{array}{l}\text { Rendah } \\
X<(\mu-1 \sigma)\end{array}$ & $X<84$ & 0 & $0 \%$ \\
\hline
\end{tabular}

\section{DISKUSI}

Penelitian ini menunjukkan bahwa mayoritas perantau Minangkabau yang berwirausaha di Medan memiliki kategori resiliensi wirausaha tinggi. Grotberg (1999) menyatakan semakin tinggi resiliensi, maka semakin baik seorang individu dalam menghadapi pengalamanpengalaman sulit. Dapat dikatakan bahwa perantau Minangkabau yang berwirausaha di Medan memiliki resiliensi yang tinggi, berarti perantau Minangkabau sangat mampu untuk menghadapi berbagai pengalaman sulit yang dihadapi selama di kota perantauan dan saat berwirausaha.

Resiliensi yang tinggi pada perantau Minangkabau dapat dipengaruhi oleh budaya Minangkabau. Budaya merupakan suatu faktor yang dapat mempromosikan resiliensi (Grotberg, 2002). Maka resiliensi wirausaha yang tinggi pada perantau Minangkabau terkait dengan budaya Minangkabau seperti yang dinyatakan oleh Ibrahim (1984) bahwa bagi orang Minangkabau tidak ragu untuk hidup di rantau yang penuh dengan kesulitan.

Kato (2005) menambahkan bahwa para perantau tidak boleh gagal dalam menjalankan misi budaya saat di kota perantauan. Jika gagal maka perantau akan dikucilkan di kampung dan harus kembali ke daerah rantau untuk berusaha lagi. Hal ini juga menjadi salah satu faktor resiliensi wirausaha yang tinggi pada perantau Minangkabau. Pelly (dalam Ibrahim, 1984) juga menyatakan bahwa orang
Tabel 2 Kategorisasi resiliensi perantau Minangkabau yang berwirausaha di Medan

\begin{tabular}{|c|c|c|c|}
\hline Dimensi Resiliensi & Mean & SD & $\mathbf{N}$ \\
\hline Regulasi emosi & $14.99^{*}$ & 2.67 & 296 \\
\hline Kontrol impuls & $17.07^{\star *}$ & 2.67 & 296 \\
\hline Optimisme & $27.74^{\star \star *}$ & 4.67 & 296 \\
\hline Analisa kausal & $15.49^{*}$ & 2.67 & 296 \\
\hline Empati & $12.94^{*}$ & 2.00 & 296 \\
\hline Self-efficacy & $28.84^{\star \star \star}$ & 4.67 & 296 \\
\hline Pencapaian & $28.53^{\star \star *}$ & 4.67 & 296 \\
\hline
\end{tabular}

Minangkabau mengajarkan sikap kemandirian saat masih anak-anak dan pemuda Minangkabau harus memiliki keterampilan seperti bela diri dan bertukang sebelum merantau.

Berdasarkan dimensi resiliensi dapat dilihat dimensi self-efficacy dan pencapaian ialah dimensi yang memilki nilai rata-rata paling tinggi. Pearson \& Hall (2006) menyatakan self-efficacy sebagai suatu keyakinan untuk mampu menyelesaikan suatu masalah, mengatasi stress, dan mampu untuk bertahan. Nilai tinggi pada aspek ini ditunjukkan dengan keyakinan individu untuk dapat menyelesaikan masalah-masalah yang kemungkinan besar dialami dan yakin individu akan sukses. Perantau Minangkabau memiliki keyakinan yang tinggi untuk sukses, yakin dapat menyelesaikan masalah dan, mampu bertahan dalam kondisi sulit.

Self- efficacy yang tinggi pada perantau Minangkabau terkait dengan karakter orang Minangkabau. Pelly (dalam Ibrahim, 1984) menyatakan orang Minangkabau memilki keinginan yang kuat untuk tetap bertahan dalam perubahan zaman. Hal ini terlihat dari konsep harga diri bagi orang Minangkabau. Berusaha mencapai kemuliaan dan kehormatan sehingga menciptakan kondisi yang kompetitif dalam masyarakat Minangkabau.

Dimensi pencapaian juga memiliki nilai rata-rata yang tinggi. Reivich \& Shatte (2002) menyatakan bahwa pencapaian 
merupakan kemampuan individu untuk mengambil peluang baru dan mencapai hal yang berbeda. Hal ini menunjukkan bahwa perantau Minangkabau yang berwirausaha di Medan dapat menemukan peluang baru dalam wirausaha dan mengejar suatu pencapaian yang berbeda di kota perantauan dibandingkan kota asal. Sesuai dengan pernyataan Kato (dalam Pelly, 1998) bahwa perantau Minangkabau harus membawa kekayaan atau prestise baru dan gagasan atau ilmu pengetahuan baru jika kembali ke kampung yang biasa disebut misi budaya dalam konteks perantauan.

Pada dimensi empati mendapatkan nilai rata-rata paling kecil diantara dimensi resiliensi lain. Menurut Reivich \& Shatte (2002) empati merupakan kemampuan individu untuk dapat membaca isyaratisyarat orang lain yang menunjukkan kondisi psikologis dan emosional orang tersebut. Dalam hal ini perantau Minangkabau yang berwirausaha di Medan kurang mampu untuk mendeskripsikan, memahami perasaan atau kebutuhan orang lain. Hal ini ditunjukkan dari isyaratisyarat seperti ekspresi wajah, nada bicara, dan bahasa tubuh. Grotberg (1999) menyatakan laki-laki kurang menunjukkan empati dibandingkan perempuan. Hal ini sesuai dengan penelitian bahwa mayoritas subjek ialah laki-laki.

Selanjutnya, kami menyadari berbagai kekurangan dari penelitian ini. Pertama, mengenai alat ukur yang digunakan dalam penelitian ini tidak mempertimbangkan jumlah aitem favorable dan aitem unfavorable. Kedua, kami tidak mempertimbangkan faktor yang mempengaruhi resiliensi seperti gender dan komunitas. Terakhir sebagai implikasi praktis, kami ingin mengajak masyarakat Minangkabau yang berada di kota perantauan agar semakin mengasah kemampuan diri yang dimiliki, mencari dukungan dari kerabat, teman, tetangga bahkan komunitas. Hal ini dapat membantu para perantau Minangkabau untuk mengatasi kesulitan yang terjadi saat merantau dan berwirausaha.

\section{REFERENSI}

Amir M. (1999). Adat Minangkabu: Pola dan Tujuan Hidup Orang Minang. Jakarta: Mutiara Sumber Widya.

Badan Pusat Statistik Provinsi Sumatera Barat. (2012). Statistik Daerah Provinsi Sumatera Barat Tahun 2012 (No.1101002.13). Padang: Badan Pusat Statistik Sumatera Barat.

Badan Pusat Statistik Provinsi Sumatera Barat (2012). Jumlah Penduduk Sumatera Barat Menurut Kabupaten/Kota, Jenis Kelamin, dan Rasio Jenis Kelamin. Diakses pada tanggal 7 Maret 2013 melalui http://sumbar.bps.go.id/web/index.php/s ubyek/kependudukan/37-penduduk/

Badan Pusat Statistik Provinsi Sumatera Utara. Data Pokok Kondisi Kesejahteraan Rakyat dan Ekonomi Provinsi Sumatera Utara Tahun 20062010. Medan: Badan Pusat Statistik Provinsi Sumtera Utara.

Barringer, B.R., Ireland, R.D. (2010). Enterpreneurship: Successfully Launch New Ventures. New Jersey: Pearson Education, Inc.

Dalton,J. H., Elias, M.J.,\& Wandersman,A. (2007). Community Psychology: Linking Individuals and Communities (edisi 2.). California: Wadsworth Thomson.

De Vries, H. Shields, M. (2005). Entrepreneurial Resilience: An Analysis of The Resilience Factors in SME Owner-Managers. New Zealand. Journal of Applied Business Christchurch College of Education.

Dewanti, R. (2008). Kewirausahaan. Jakarta: Mitra Wacana Media.

Everall, R. (2006) . Creating a Future: A Study of Resilience in Suicidal Female Adolescent. Journal of Counseling and Development. 
Grotberg, E. H. (1999). Tapping Your Inner Strength. USA: New Harbinger Publications. Inc.

Grotberg, E. H. (2003). Resilience for Today: Gaining Strength from Adversity. Westport: Preger Publishers.

Ibrahim, A. (1984). Persepsi Minangkabau Minangrantau. Medan: Fa. Madju.

Kato, T. (2005). Adat Minangkabau dan Merantau: dalam Perspektif Sejarah. Jakarta: Balai Pustaka.

Murad, A. (1980). Merantau: Outmigration in a Matrilineal Society of West Sumatra. Canberra: Australia National University.

Pelly, U. (1998). Urbanisasi dan Adaptasi: Peranan Misi Budaya Minangkabau dan Mandailing. Jakarta: Pustaka LP3ES.

Pearson, J., Hall, D. K. (2006) Reaching IN... Reaching OUT Resiliency Guidebook. The Child Development Institute. University of Toronto.

Reich. J. W., Zautra. A. J. \& Hall, J.S. (2010). Handbook of Adult Resilience. New York : The Guilford Press.

Revich, K., Shatte, A. (2002). The Resilience Factor. New York: Random House. Inc.

Siebert, A. (2005). The resilience advantage: Maser change, thrive under pressure, and bounce back from setbacks. San Fransisco: BerrettKoehler publishers, inc.

Suryadinata, L. Arifin, E.N, \& Ananta, A. (2003). Penduduk Indonesia: Etnis dan agama dalam era perubahan politik. Jakarta: LP3ES.

Suster, M. (2009). What Makes an Entrepreneur-Resiliency. (Online). (diakses pada tanggal 22 Maret 2013 http://www.bothsidesofthetable.com/20 09/12/18/what-makes-an-entrepreneur410-resiliency/).
Sun, J., Buys, N., Wang, X. C., \& Stewart, D. (2011). Entrepreneurs' Resilience and Its Relationship with Entrepreneurial Type: A Study of National Chinese Entrepreneur Sample. Brisbane, Australia: Griffth University, School of Public Health. 